\title{
Improvement of sexual function after transobturator tape procedure in women with stress urinary incontinence
}

\author{
M. Arts-de Jong • A. M. van Altena • C. I. M. Aalders • \\ F. P. H. L. J. Dijkhuizen • M. R. van Balken
}

Received: 24 September 2010 / Accepted: 21 November 2010/Published online: 5 January 2011

(C) The Author(s) 2010. This article is published with open access at Springerlink.com

\begin{abstract}
Sling procedures are a widely proven treatment for stress urinary incontinence. The aim of this prospective study was to evaluate the effect of the transobturator tape on female sexual functioning. Fifty-four women treated for stress urinary incontinence with transobturator tape filled out self-administered questionnaires on quality of life, urinary incontinence, and sexual function prior to surgery and 6 weeks and 12 months postoperatively. Preoperatively, 40 women $(78 \%)$ were sexually active. There were no significant postoperative changes regarding frequency of sexual activity, sexual desire, and problems with lubrication or orgasm. Preoperatively, 55\% reported urinary leakage during sexual activity and after surgery $6.5 \%$. Sexual satisfaction was significantly improved 6 weeks $(p=0.05)$ and 12 months $(p=0.03)$ postoperatively. Pain during or after sexual activity was declined, only one patient reported worsening of pain. The transobturator tape procedure has a positive effect on female sexual functioning by reducing urinary leakage and pain during or after sexual activity. It seems to improve the overall sexual satisfaction. Further research is warranted to support these preliminary findings.
\end{abstract}

M. Arts-de Jong ( $\bowtie)$

Department of Obstetrics and Gynecology,

Radboud University Medical Centre,

P.O. BOX 9101, 6500 HB Nijmegen, The Netherlands

e-mail: M.deJong@obgyn.umcn.nl

A. M. van Altena - C. I. M. Aalders · F. P. H. L. J. Dijkhuizen Department of Obstetrics and Gynecology, Rijnstate Hospital, Arnhem, The Netherlands

M. R. van Balken

Department of Urology, Rijnstate Hospital,

Arnhem, The Netherlands
Keywords Transobturator tape (TOT) - Stress urinary incontinence $\cdot$ Female sexual function $\cdot$ Sexual satisfaction

\section{Background}

Sexual dysfunction is a common condition in women with pelvic floor disorders, especially with stress urinary incontinence [1-3]. The prevalence of urinary incontinence varies widely and increases with age [4]. Urinary incontinence has a negative impact on quality of life, social, physiological, physical, and sexual well-being in women [3, 5-7].

In 1995, Ulmsten et al. [8] initially described the development of a minimally invasive tension-free vaginal tape (TVT). The transobturator tape (TOT) procedure was developed by Delorme [9] to reduce the complications associated with the TVT, including bladder perforation, urinary retention, and bowel injury. Nowadays, suburethral slings have become a standard surgical procedure for treatment of stress urinary incontinence when conservative therapy has failed.

The effect of TVT on sexual functioning has been studied, but the results are still inconsistent [10-15]. Treatment of stress urinary incontinence by a suburethral sling could have a positive influence on sexual functioning by decreasing urinary leakage during intercourse and improving body image as a result of declining urinary incontinence [10, 13, 16, 17]. Suburethral sling procedures have a potential risk of neurovasculair injuries. On the other hand, sexual function may worsen by developing dyspareunia after the suburethral sling procedure [18]. De novo dyspareunia could be explained by the position of the tape, especially in the paraurethral folds, vaginal narrowing, or erosions [19-21]. The aim of this study was to evaluate the effect of TOT for stress urinary 
incontinence on sexual functioning and sexual satisfaction in women.

\section{Methods}

\section{Patients}

A prospective observational study was performed in the Departments of Gynecology and Urology of the Rijnstate Hospital, Arnhem, The Netherlands.

All patients who underwent a tension-free TOT outsidein procedure (Uretex $\mathrm{TO}^{\circledR}, \mathrm{BARD}$, New Jersey, USA) for stress urinary incontinence from April 2005 till June 2006 were invited to participate in the study. Patients were selected on basis of symptoms of stress urinary incontinence and the diagnosis was confirmed by urodynamic investigation. Exclusion criteria were inability to communicate in Dutch, a maximum bladder capacity of less than $200 \mathrm{ml}$, severe complaints of urge urinary incontinence and/ or detrusor overactivity on urodynamic investigation, and urinary tract infection not responding on therapy. All women underwent gynecological examination, urine dipstick, urodynamics including filling cystometry, pressureflow studies, and urethral profilometry prior to surgery.

All patients enrolled were invited to fill out the Incontinence Quality of Life Questionnaire (I-QoL), the Urinary Distress Inventory (UDI) and the Nine Questions on Sexual Functioning (NSF-9), prior to surgery, 6 weeks postoperatively and 12 months after surgery. Data on UDI scores after 12 months are missing as a result of problems with filling out the questionnaires. All women were asked to give informed consent. The study was approved by the medical ethics committee of the Rijnstate Hospital.

\section{Instruments}

The I-QoL is a 22-item quality of life instrument specific to persons with stress and mixed types of urinary incontinence. All items are scored on a five-point Likert response scale. There are three subscales; avoidance and limiting behaviors, psychosocial impacts, and social embarrassment. The sum score is transformed to a $0-100$ scale. Higher scores indicate better quality of life [22, 23].

Furthermore, data on urinary incontinence are obtained using the UDI $[24,25]$. The UDI consists of 19 items and every item consists of two parts: whether or not a symptom is present and the amount of bother related to that symptom. Five subscales are identified: discomfort/pain, urinary incontinence, overactive bladder, genital prolapse, and obstructive micturition. Total scores are converted to a score range of 0-300 with higher scores representing greater symptom distress.
The NSF-9, a Dutch-language self-reported standardized questionnaire, contains questions on sexual desire, frequency of sexual activity, lubrication, orgasm, pain during or after sexual activity, and sexual satisfaction. We have added one question on urinary leakage during sexual activity. The NSF does not differentiate between leakage at penetration or during organism. This questionnaire is originally developed to measure the influence of medication on sexual functioning, however is also been used in treatment modalities like percutaneous tibial nerve stimulation [26]. The severity of symptoms is quantified using a five-point Likert scale. There is no sum score and only individually scores on each question are used.

\section{Statistical analysis}

Non-parametric tests (Wilcoxon signed-rank test) were applied as the data were not normally distributed. Statistical analyses were performed using SPSS 16.0.

\section{Findings}

Of all 59 women who underwent a TOT procedure in the study period, 54 (92\%) agreed to participate in the study. Mean age was 52 (range: 37-78 year). Nulliparity applied to two women $(3.8 \%)$, while median parity was two (range $1-5)$. Twenty-three women (43\%) were postmenopausal. All women had stress urinary incontinence, in $83 \%$ daily stress urinary incontinence was reported. The other women had stress urinary incontinence at least once a week. Nineteen women (35\%) reported mild to moderate complaints of urge urinary incontinence.

Mean operative time was 24 min (standard deviation, SD: 6). In seven cases, the TOT procedure was combined with another operation: in four women, a vaginal wall correction; in two women, a laparoscopy; and in one, a curettage and balloon ablation. This combination of operations did not significantly change the mean operative time. There were no reports of intraoperative complications. The mean blood loss was $50 \mathrm{ml}$ (SD 93; range 0-500).The subjective cure rate of stress urinary incontinence was $85 \%$ and the other women (15\%) reported an improvement of the stress urinary incontinence at 6 weeks. The total UDI score prior to surgery was 172 (SD 86). Six weeks postoperatively, this score significantly decreased to 70 (SD 70; $p<0.001$ ). The I-QoL questionnaire parameters were significantly improved 6 weeks postoperatively (65.8\% (SD 18.1) versus 91.8\% (SD 14.7); $p<0.001$ ). No further changes occurred in the I-QoL score 1 year after surgery $(91.0 \%$ (SD 18.5)). Urge urinary incontinence disappeared in 13 women (65\%). Two patients $(3.7 \%)$ reported worsening of urge urinary incontinence. De novo 
urgency urinary incontinence was found in four patients $(7 \%)$. Five patients $(9.3 \%)$ reported postoperative complications for which reoperation was indicated. Voiding difficulties requiring tape section occurred in two patients (3.7\%). Two patients $(3.7 \%)$ had a partial removal of the tape within 1 year of the initial operation because of vaginal erosions; one of them had a spontaneous drainage of a vaginal abscess before reoperation. One patient was reoperated at 21 days after primary surgery for persistent vaginal blood loss from wound dehiscention. The defect in the vaginal wall was closed and the TOT stayed in situ.

Of all 54 women, 40 (78\%) were sexually active in the month prior to surgery. Sixteen women $(31 \%)$ had feelings of sexual desire once a week or more. Forty percent of these women reported being sexual active once a week or more. Urinary loss during sexual activities was identified in 22 women (55\%). One fourth of the women had experienced lubrication problems, while $40 \%$ of the women never or just occasionally achieved an orgasm. Pain during and after sexual activity was mentioned by $55 \%$; of those women, $12.5 \%$ experienced this pain frequently. Thirty eight percent of all women had a satisfactory sexual life.

No significant differences were reported on sexual desire, frequency of sexual activity, and problems with lubrication and orgasm 6 weeks postoperatively and 12 months after surgery. However, urinary leakage during sexual activity was significantly improved after the TOT procedure. Six weeks postoperatively, $88.5 \%$ had no urinary loss during sexual activity and 12 months after surgery $93.5 \%$ of the women mentioned no urinary loss. Compared to prior to surgery, satisfaction with current sexual life was increased at 6 weeks $(52 \% ; p=0.048)$ and 12 months $(58 \% ; p=0.029)$. Pain during and after sexual activity was significantly diminished 12 months after surgery $(p=0.019)$. Only one patient reported an increase in pain during and after sexual activity.

\section{Conclusions}

We present prospective data on the effect of TOT on sexual functioning in women. Our findings suggest that the TOT procedure seems to have a positive influence on female sexual functioning by reducing the urinary leakage during sexual activity and declining the experience of pain during or after sexual activity. The overall sexual satisfaction with current sexual life seems to improve after the TOT procedure.

Few studies have evaluated sexual function following sling procedures and the results are not consistent. For the TOT procedure, Sentilhes [27] reported 31\% improvement in intercourse satisfaction and $10 \%$ deterioration. The TVT procedure and its effect on sexual functioning has been the subject of several studies. Some studies showed an overall positive effect on sexual function after surgery [10, 12], while other studies suggest that sexual function is not changed [11, 15] or worsened [18] by the TVT procedure.

The TOT procedure could have a positive outcome on female sexual function by reducing the urinary leakage during sexual activity. Our data showed a significant decline in urinary leakage during sexual activity after surgery. In a study by Serati et al. [16], between $10 \%$ and $27 \%$ of women with urinary incontinence reported urinary leakage during intercourse. They suggested an association between urinary leakage at penetration and stress urinary incontinence as well as urinary leakage during orgasm and detrusor overactivity. Unfortunately, the NSF does not differentiate between the moment of urinary leakage during intercourse. Bekker et al. [28] showed that women with coital incontinence had a higher improvement in sexual intercourse after surgery compared to women without coital incontinence. Berthier et al. [11] also reported that women with coital incontinence were more likely to report improvement of their sexual function after the TVT procedure. Both studies only reported improvement in sexual intercourse or sexual function; however, they do not mention sexual satisfaction. Moreover, we found a significant improvement of satisfaction with sexual function after surgery. It is known that sexual function and sexual satisfaction not always correlate. It is good to know that sexual function enhances, but it seems even better that sexual satisfaction improves after sling procedures.

Another explanation for the positive effect of sling procedures on sexual function is the enhancement of the body image of women just by reducing stress urinary incontinence. Temml et al. [3] reported that $25 \%$ of women had impairment of their sexual life by urinary incontinence. The cure rate of incontinence after sling procedures is very high. All women in our study had improvement of their stress urinary incontinence and the total subjective cure rate was $85 \%$. Achtari [17] suggested that reducing urinary incontinence improves overall sexual function by increasing body image and self esteem.

Sexual function may be negatively influenced by the effects of the TOT procedure itself. It must be assumed that sling procedures can damage vascular and neural structures causing worsening of the sexual function. Caruso et al. [29] studied the effect of TVT and TOT on clitoral blood flow using color Doppler ultrasonography. They found that clitoral blood flow negatively changed after TVT, whereas TOT had no influence at all. The anatomical course of TOT showed that the tape is not in contact with major neurovascular structures [30]. Delmas [30] suggested that TOT constitutes an anatomically safer approach than minimally invasive retropubic tape techniques. Nevertheless, an altered vaginal anatomy as a result of the TOT procedure 
may result in sexual dysfunction. Elzevier et al. [20] reported that TOT provided more sexual dysfunction than tension-free vaginal tape obturator because the TOT procedure causes more pain during intercourse as a result of vaginal narrowing. One of their explanations for vaginal narrowing is that more vaginal tissue in the outside-in procedure is included. Ten percent of the partners of women receiving a TOT experienced vaginal narrowing. However, Weber et al. [31] showed that patients' symptoms did not correlate with objective measures of vaginal dimensions of introital caliber and vaginal length after prolapse and incontinence surgery. Further research could be done on subjective and objective measures of vaginal dimensions after TOT procedures. Cholhan [21] firstly described paraurethral banding associated with dyspareunia after TOT procedure. By examination postoperatively, anterior vaginal wall banding in the paraurethral folds immediately adjacent to the midurethral placement of the sling was felt. Further prospective research must be done on this newly described phenomena.

Erosions are a concern for inorganic synthetic sling materials and happen in $5 \%$ of cases using polypropylene slings [19]. Suburethral erosions can cause de novo dyspareunie. Kuhn et al. [32] reported that sexual function is improved after treating erosions by resuturing. Our results showed one woman with an increase in pain during and after sexual activity, but there was no vaginal erosion.

Our study has some limitations. Firstly, it should be taken into account that inconsistent definitions of sexual function make it difficult to compare prevalence with other studies. Secondly, there was no Dutch-validated questionnaire available to evaluate the sexual functioning in women with pelvic floor disorders, like stress urinary incontinence. Rogers et al. [33] developed a condition-specific validated instrument to measure sexual function in women with urinary incontinence or pelvic organ prolapsed, called Pelvic Organ Prolapse-Urinary Incontinence Sexual Function Questionnaire. This questionnaire is translated in Dutch and the validation is in progress. This instrument contains 31 items divided in three domains, labeled behavioral/emotive, physical, and partner-related and it can be useful in further research on sexual function and urinary incontinence. The questionnaire that was used in our study, NSF-9, was validated and used in previous studies on the effect of percutaneous tibial nerve stimulation on sexual functioning in patients with lower urinary tract dysfunction. Another limitation was the relatively small sample size. Additional, larger prospective studies using validated condition-specified instruments are needed to support our preliminary findings and to compare sexual function after TVT versus TOT procedures for stress urinary incontinence.
In conclusion, we showed that the TOT procedure improves female sexual functioning and overall sexual satisfaction mainly by reducing the urinary leakage during sexual activity and declining the experience of pain during or after sexual activity. Further research is warranted to support these preliminary findings.

Declaration of interest The authors report no conflicts of interest. The authors alone are responsible for the content and writing of the paper.

Open Access This article is distributed under the terms of the Creative Commons Attribution Noncommercial License which permits any noncommercial use, distribution, and reproduction in any medium, provided the original author(s) and source are credited.

\section{References}

1. Handa VL, Harvey L, Cundiff GW, Siddique SA, Kjerulff KH (2004) Sexual function among women with urinary incontinence and pelvic organ prolapse. Am J Obstet Gynecol 191(3):751-756

2. Salonia A, Zanni G, Nappi RE, Briganti A, Deho F, Fabbri F, Colombo R, Guazzoni G, Di Girolamo V, Rigatti P, Montorsi F (2004) Sexual dysfunction is common in women with lower urinary tract symptoms and urinary incontinence: results of a cross-sectional study. Eur Urol 45:642-648

3. Temml C, Haidinger G, Schmidbauer J, Schatzl G, Madersbacher S (2000) Urinary incontinence in both sexes: prevalence rates and impact on quality of life and sexual life. Neurourol Urodyn 19 (3):259-271

4. Minassian VA, Drutz HP, Al-Badr A (2003) Urinary incontinence as a worldwide problem. Int J Gynaecol Obstet 82:327-338

5. Tennstedt SL, Fitzgerarld MP, Nager $\mathrm{CW}, \mathrm{Xu}$ Y, Zimmern $\mathrm{P}$, Kraus S, Goode PS, Kusek JW, Borello-France D, Mallett V (2007) Quality of life in women with stress urinary incontinence. Int Urogynecol J Pelvic Floor Dysfunct 18(5):543-549

6. Yip SK, Chan A, Pang S, Leung P, Tang C, Shek D, Chung T (2003) The impact of urodynamic stress incontinence and detrusor overactivity on marital relationship and sexual function. Am J Obstet Gynecol 188:1244-1248

7. Yip SK, Cardozo L (2007) Psychological morbidity and female urinary incontinence. Best Pract Res Clin Obstet Gynaecol 21 (2):321-329

8. Ulmsten U, Henriksson L, Johnson P, Varhos G (1996) An ambulatory surgical procedure under local anesthesia for treatment of female urinary incontinence. Int Urogynecol J Pelvic Floor Dysfunct 7(2):81-85

9. Delorme E (2001) Transobturator urethral suspension: miniinvasive procedure in the treatment of stress urinary incontinence in women. Prog Urol 11(6):1306-1313

10. Ghezzi F, Serati M, Cromi A, Uccella S, Triacca P, Bolis P (2006) Impact of tension-free vaginal tape on sexual function: results of a prospective study. Int Urogynecol J Pelvic Floor Dysfunct 17 (1):54-59

11. Berthier A, Sentilhes L, Taibi S, Loisel C, Grise P, Marpeau L (2008) Sexual function in women following the transvaginal tension-free tape procedure for incontinence. Int $\mathrm{J}$ Gynaecol Obstet 102(2):105-109

12. Elzevier HW, Venema PL, Lycklama a Nijeholt AAB (2004) Sexual function after tension-free vaginal tape (tvt) for stress urinary incontinence: results of a mailed questionnaire. Int Urogynecol J 15:313-318 
13. Jha S, Radley S, Farkas A, Jones G (2009) The impact of tvt on sexual function. Int Urogynecol J 20:165-169

14. Serati M, Salvatore S, Uccella S, Zanirato M, Cattoni E, Nappi RE, Bolis P (2009) The impact of the mid-urethral slings for the treatment of stress urinary incontinence on female sexuality. J Sex Med 6:1534-1542

15. Maaita C, Bhaumik J, Davies AE (2002) Sexual function after using tension-free vaginal tape for surgical treatment of genuine stress incontinence. BJU Int 90:540-543

16. Serati M, Salvatore S, Uccella S, Nappi RE, Bolis P (2009) Female urinary incontinence during intercourse: a review on an understudied problem for women's sexuality. J Sex Med 6:40-48

17. Achtari C, Dwyer PL (2005) Sexual function and pelvic floor disorders. Best Pract Res Clin Obstet Gynaecol 19(6):993-1008

18. Mazouni C, Karsenty G, Bretelle F, Bladou F, Gamerre M, Serment G (2004) Urinary complications and sexual function after the tension-free vaginal tape procedure. Acta Obstet Gynecol Scand 83(10):955-961

19. Clemens JQ, DeLancey JO, Faerber GJ, Westney OL, Mcguire EJ (2000) Urinary tract erosions after synthetic pubovaginal slings: diagnosis and managment strategy. Urology 56(4):589-594

20. Elzevier HW, Putter H, Delaere KPJ, Venema PL, Lycklama a Nijeholt AAB, Pelger RCM (2008) Female sexual function after surgery for stress urinary incontinence: transobturator suburethral tape vs tension-free vaginal tape obturator. J Sex Med 5(2):400-406

21. Cholhan HJ, Hutchings TB, Rooney KE (2010) Dyspareunie associated with paraurethral banding in the transobturator sling. Am J Obstet Gynecol 202(5):e481-e485

22. Wagner TH, Patrick DL, Bavendam TG (1996) Quality of life of persons with urinary incontinence: development of a new measure. Urology 47:67-72

23. Patrick DL, Martin ML, Bushnell DM, Yalcin I, Wagner TH, Buesching DP (1999) Quality of life of women with urinary incontinence: further development of the incontinence quality of life instrument (i-qol). Urology 53:71-76

24. Shumaker SA, Wyman JF, Uebersax JS, McClish D, Fantl JA (1994) Health-related quality of life measures for women with urinary incontinence: the incontinence impact questionnaire and the urogenital distress inventory. Continence program in women (cpw) research group. Qual Life Res 3:291-306

25. van der Vaart CH, de Leeuw JRJ, Roovers JWR, Heintz APM (2003) Measuring health-related quality of life in women with urogenital dysfunction: the urogenital distress inventory and incontinence impact questionnaire revisited. Neurourol Urodyn 22:97-104

26. van Balken MR, Vergunst H, Bemelmans BL (2006) Sexual functioning in patients with lower urinary tract dysfunction improves after percutaneous tibial nerve stimulation. Int J Impot Res 18(5):470-475

27. Sentilhes L, Berthier A, Caremal R, Loisel C, Marpeau L, Grise P (2008) Sexual function after transobturator tape procedure for stress urinary incontinence. Urology 71(6):1074-1079

28. Bekker M, Beck J, Putter H, Venema PL, Lycklama a Nijeholt A, Pelger R, Elzevier H (2009) Sexual function improvement following surgery for stress incontinence: the relevance of coital incontinence. J Sex Med 6(11):3208-3213

29. Caruso S, Rugolo S, Bandlera S, Mirabella D, Cavallaro A, Clanci A (2007) Clitoral blood flow changers after surgery for stress urinary incontinence: pilot study on tvt versus tot procedures. Urology 70:554-557

30. Delmas V (2005) Anatomical risks of transobturator suburethral tape in the treatment of female stress urinary incontinence. Eur Urol 48:793-798

31. Weber AM, Walters MD, Piedmonte MR (2000) Sexual function and vaginal anatomy in women before and after surgery for pelvic organ prolapse and urinary incontinence. Am J Obstet Gynecol 182(6):1610-1615

32. Kuhn A, Eggeman C, Burkhard F, Mueller MD (2009) Correction of erosion after suburethral sling insertion for stress incontinence: results and related sexual function. Eur Urol 56(2):371-376

33. Rogers RG, Kammerer-Doak D, Villarreal A, Coates K, Qualls C (2001) A new instrument to measure sexual function in women with urinary incontinence or pelvic organ prolapse. Am J Obstet Gynecol 184:552-558 